\title{
Performance of slow-release formulations of alachlor
}

Tomás Undabeytia ${ }^{1}$, Fátima Sopeña ${ }^{1}$, Trinidad Sánchez-Verdejo ${ }^{1}$, Jaime Villaverde ${ }^{1}$, Shlomo Nir ${ }^{2}$, Esmeralda Morillo ${ }^{1}$, Celia Maqueda ${ }^{1}$.

1. Institute of Natural Resources and Agrobiology (CSIC). Reina Mercedes 10. Apdo. 1052. 41080 Seville. Spain.

2. The Faculty of Agricultural, Food and Environmental Quality Sciences, Hebrew University of Jerusalem. P.O. Box 12. Rehovot 76100. Israel.

Short title: Slow release formulations of alachlor

*Corresponding author; phone: +34-954624711; fax: +34-954624002; e-mail: undabeyt@,irnase.csic.es

\section{ACKNOWLEDGMENTS}

The authors acknowledge financial support by the Spanish Foreign Ministry (Project A/016047/08) and Junta de Andalucía (Project P06-FQM-1909). 


\title{
Performance of slow-release formulations of alachlor
}

\begin{abstract}
Alachlor [2-chloro-N-(2,6-diethylphenyl)-N-(methoxymethyl)acetamide] is a widely used herbicide that has been identified as a groundwater contaminant. Several slow-release formulations (SRFs) of this herbicide have been examined for their capacity to reduce its leaching and enhance weed control. A field experiment was performed to determine alachlor leaching and bioefficacy in: (i) a commercial formulation, Alanex, (ii) SRFs based on ethylcellulose (EC) microencapsulation or phosphatidylcholine (PC)-montmorillonite complexes. Alachlor distribution within the top $30 \mathrm{~cm}$ of the soil layer was modeled with the pesticide-leaching model PEARL, using release constants for the SRFs obtained from in-vitro experiments. Compared to the commercial formulation, leaching to the $20-$ to $30-\mathrm{cm}$ depth was reduced by $33 \%$ for EC and $25 \%$ for PC-clay formulations, but only in the latter was herbicide bioefficacy retained. The poor bioefficacy of the EC formulations can be explained by their very slow release properties, which may nevertheless confer an advantage under prolonged heavy rainfall. The model yielded good predictions for the residual amounts of herbicide at 59 and $99 \mathrm{~d}$ after treatment (DAT). At 191 DAT, the amounts of alachlor at 0 - to $20-\mathrm{cm}$ depth were overestimated by 13 to $23 \%$, indicating limitations of the model at longer times, attributed to: (i) the adaptation time of the microbial population for herbicide degradation and (ii) the effect of herbicide sequestration in the soil matrix, a phenomenon denoted as "aging".
\end{abstract}


1 Abbreviations: SRF: slow-release formulation; EC: ethylcellulose; PC:

2 phosphatidylcholine; a.i.: active ingredient; RMSE: root mean square error; DAT: days

3 after treatment; AEW: acetone/ethyl acetate/water

4 
2 Herbicide mobility in soils causes: (i) groundwater contamination, (ii) reduced

3 herbicidal activity and crop yield due to herbicide leaching below the weed seed zone,

4 and (iii) surface migration of the herbicide which can harm neighboring crops (Weber et

5 al., 1999). SRFs of herbicides are designed to maintain the threshold concentration of

6 the active ingredient for weed control in the soil by providing release at the required

7 rate. The consequent lowering of the required amounts of herbicide is both

8 environmentally friendly and economically advantageous.

Ethylcellulose (EC)-based formulations of the herbicides norflurazon and

10 alachlor have been obtained by the solvent-evaporation technique (Fernández-Urrusuno

11 et al., 2000; Sopeña et al., 2005). The release rate of the active ingredient from EC-

12 based formulations depends on the pesticide-to-EC ratio and is strongly correlated with

13 the size of the microcapsule (Pérez-Martínez et al., 2001; Morillo et al., 2004). In soils,

14 with limited alachlor persistence, the use of EC-based formulations of the herbicide

15 reduced its loss by $54 \%$ relative to the use of a commercial formulation (Sopeña et al.,

16 2008). Similarly, the leaching of alachlor from the EC formulations was significantly

17 reduced in soil column experiments over the commercial formulation (Sopeña et al., 18 2007).

19 A new approach for the development of SRFs of herbicides consists of their

20 incorporation in micelles or vesicles of alkylammonium quaternary cations adsorbed on

21 clay minerals (Nir et al., 2006). An optimal vesicle-clay formulation of anionic

22 herbicides, in which a large fraction of the herbicide is adsorbed by the vesicle/micelle-

23 clay complex, can be obtained for particular vesicle (or micelle)-clay ratios, such that

24 most of the vesicles or micelles are adsorbed without undergoing premature

25 decomposition (Mishael et al., 2002a; Undabeytia et al., 2004). Clay-vesicle (micelle) 
1 formulations of sulfonylurea herbicides have been shown to reduce the amount of

2 leached herbicide several-fold and enhanced its biological activity in the upper soil layer

3 (Mishael et al., 2002b, 2003; Undabeytia et al., 2003). These formulations provide weed

4 control at much lower rates than with commercial formulations. Recently, surfactants

5 were replaced with the EPA-approved substance phosphatidylcholine (PC) (Sánchez-

6 Verdejo et al., 2008a). PC-clay formulations of atrazine and alachlor have enabled

7 reducing the doses of these herbicides to below the recommended values (Sánchez-

8 Verdejo et al., 2008b).

9 In the current study, the performance of SRFs of the herbicide alachlor using

10 EC-based microcapsules and PC-clay complexes was compared, the criteria being their

11 ability to reduce leaching while maintaining herbicide activity. Such studies are scarce,

12 and alachlor was selected because it is a widely used herbicide in the United States

13 (Boparai et al., 2006) and Europe (Sánchez-Camazano et al., 2005).

14 The use of mathematical models for predicting the environmental fate of

15 pesticides is becoming increasingly common. Pesticide-leaching models can be divided

16 into chromatographic flow models, which are based on the convection/dispersion

17 equation, and preferential flow models (Scorza et al., 2005). The Pesticide Emission

18 Assessment at Regional and Local scales model (PEARL model) (Tiktak et al., 2000) is

19 one of the chromatographic models that has been adopted by the European Union in

20 their pesticide-regulation scheme.

21 The objectives of this work were: (i) to evaluate the performance of SRFs of the

22 herbicide alachlor that use two different methodologies to reduce leaching and maintain

23 herbicide efficacy in field experiments in comparison to a commercial formulation, and

24 (ii) to test the validity of the PEARL model in simulating alachlor leaching. 


\section{MATERIALS AND METHODS}

Field experiments

A field experiment was conducted to test and compare the efficiency of the PC- and EC-based alachlor formulations. The experiment was carried out in a sandy loam soil classified as a Typic Calcixerept (Soil Survey Staff, 2006) located at "La

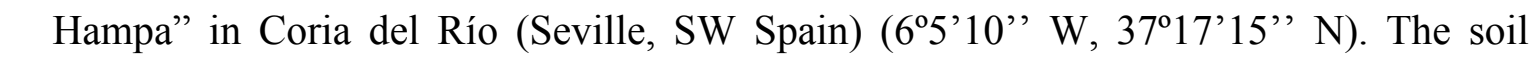
contained $49 \mathrm{~g} \mathrm{~kg}^{-1}$ of $\mathrm{CaCO}_{3}, 13.6 \mathrm{~g} \mathrm{~kg}^{-1}$ of organic matter and its $\mathrm{pH}$ was 8.9 . The particle-size distribution was: $131 \mathrm{~g} \mathrm{~kg}^{-1}$ clay, $68 \mathrm{~g} \mathrm{~kg}^{-1}$ silt, and $801 \mathrm{~g} \mathrm{~kg}^{-1}$ sand. The study treatments were a commercial formulation (Alanex), two EC (A14 and A18), and two PC-clay (A5/8 and A1.6/14) formulations. The commercial formulation was applied as a stable emulsion, and the SRFs were applied as aqueous suspensions. All of the formulations were sprayed on November 21, 2006, and left on the soil surface. The applied rate was $3 \mathrm{~kg} \mathrm{ha}^{-1}$.

A completely randomized experimental design (three replicates per treatment) was conducted in 18 subplots $(1 \mathrm{~m} \mathrm{x} 1 \mathrm{~m})$. A commercial formulation, two PC-clay, and two ethylcellulose based-formulations were tested versus a control. Oat (Avena sativa L.) $\left(30 \mathrm{~g} \mathrm{~m}^{-2}\right)$ was sown in all plots. At selected times after herbicide application $(59,99$, and 191 d), soil samples of each plot were taken from different soil depths $(0$ to $-10,10$ to -20 and 20 to $-30 \mathrm{~cm})$ using a small auger probe. No irrigation was applied. The plots received 46, 158, and $247 \mathrm{~mm}$ of rain before the first, second, and third sampling, respectively.

The amount of alachlor at each depth was extracted in triplicate using $2 \mathrm{~g}$ of soil and $10 \mathrm{~mL}$ of methanol, and equilibrated for $24 \mathrm{~h}$ under continuous shaking. The suspensions were centrifuged and the supernatant was analyzed for the herbicide concentration. Preliminary experiments with non-treated soil spiked with aliquots of 
1 herbicide solutions showed full recovery of the herbicide. At the end of the experiment

2 on May 30, 2007, the plant shoots were harvested and the bioefficacy of alachlor was

3 evaluated by weighing the fresh shoots.

4

\section{Preparation of alachlor-PC-clay formulations}

The PC formulations of alachlor were prepared by dissolving different amounts of the herbicide in a $6 \mathrm{mM}$ PC solution by sonication, and further addition to montmorillonite, which sorbs PC-alachlor complexes. The added concentrations of herbicides were 8.0 and $14.0 \mathrm{mM}$ for 5 and $1.6 \mathrm{~g} \mathrm{~L}^{-1}$ clay, respectively. After shaking for $24 \mathrm{~h}$, the suspensions were centrifuged at $12100 \mathrm{~g}$ for $20 \mathrm{~min}$. The supernatants were analyzed for the remaining herbicide and the pellets were freeze-dried to yield the final formulations. Additional details of the preparation are found in Sánchez-Verdejo et al. (2008a). A nomenclature was introduced for PC-clay formulations (Table 1) where the first letter (A) indicates alachlor, the first number denotes the clay concentration and the second number gives the initial herbicide concentration used. The active ingredient (a.i.) was determined for each formulation by measuring the herbicide concentration in solution by HPLC after sonicating $5 \mathrm{mg}$ of the formulation with $10 \mathrm{~mL}$ of methanol in duplicate.

Preparation of the alachlor-ethylcellulose (EC) formulations.

The ethylcellulose-alachlor formulations were prepared by the oil-in-water emulsion solvent evaporation technique, using polyvinyl alcohol (PVA) as the emulsifier and two types of EC with different viscosities (EC10 and EC40) as the matrix polymer (Sopeña et al., 2005). Briefly, $1 \mathrm{~g}$ of polymer and 0.2 or $0.3 \mathrm{~g}$ of herbicide were dissolved in $15 \mathrm{~mL}$ of chloroform at room temperature. The herbicide- 
1 polymer solution was then emulsified into an aqueous phase by dropwise addition into

$2150 \mathrm{~mL}$ of aqueous solution containing $0.15 \%$ of PVA while stirring at either 600 or

$3300 \mathrm{rpm}$. Two formulations (A14 and A18) were prepared using different experimental

4 conditions. The A14 formulation used EC40, a 3.33:1 EC/A ratio, and a stirring speed

5 of $600 \mathrm{rpm}$. A18 was prepared by using EC10, a 5:1 EC/A ratio, a stirring speed of 300

$6 \mathrm{rpm}$, and polyethylene glycol (PEG) as a channel forming agent, which was added to

7 the polymer solution $(40 \% \mathrm{w}: \mathrm{w})$ before the formation of the emulsion with the aqueous

8 phase. The active ingredient was determined by measuring the herbicide concentration

9 by HPLC after dissolving $5 \mathrm{mg}$ of each formulation in methanol in duplicate.

\section{Water release kinetics}

12 Release tests of alachlor formulations were performed in duplicate with a rotating 13 paddle apparatus (Sotax). For each formulation, $5 \mathrm{mg}$ of alachlor were added to $1 \mathrm{~L}$ of 14 deionized water at $25^{\circ} \mathrm{C}$ and stirred at $50 \mathrm{rpm}$. At appropriate time intervals from 0 to 96 $15 \mathrm{~h}$, samples were taken, passed through PTFE filters, and the herbicide was analyzed. 16 Alachlor was analyzed by HPLC (Shimadzu Model 10A) equipped with a PDA 17 detector. The reverse phase column was a $15 \mathrm{~cm}$ Kromasil $100 \mathrm{C} 18$, and the flow rate 18 was $1.0 \mathrm{~mL} \mathrm{~min}^{-1}$. The mobile phase was $60 \%$ acetonitrile and $40 \%$ water. The 19 wavelength was set at $220 \mathrm{~nm}$, and the retention time was $6.26 \mathrm{~min}$.

\section{Modeling of leaching}

The chromatographic flow model PEARL (version 3.3.3) was used for 23 calculating the distribution of alachlor into the soil for the applied formulations. Soil 24 hydraulic properties were introduced by using the retentivity-conductivity relationships 25 of Van Genuchten (1980) and Mualem (1976). Pesticide physicochemical parameters, 
1 such as molecular weight, vapor pressure, and water solubility were taken from the

2 literature (Tomlin, 2003). Additional input parameters were the sorption coefficient

3 normalized to the organic matter content $\left(\mathrm{K}_{\mathrm{om}}\right)$ and the degradation half-life time in soil,

4 which were determined from adsorption and incubation experiments in non-treated soil,

5 respectively. The cropping scenario was winter cereal oats, with an alachlor application

6 rate of $3 \mathrm{~kg}$ of $a . i$ ha $^{-1}$. Mean daily values of temperature and rainfall were taken from

7 the meteorological station located on the farm.

9 by Ford et al. (2007) based on the optional use of a subroutine to include the

10 degradation of the herbicide to its metabolites. The release of the active substance from

11 the formulation is simulated simply as the degradation of parent to metabolite $\left(\mathrm{t}_{1 / 2}(2)\right)$

12 and the $\mathrm{K}_{\mathrm{om}}$ of the parent was set to the maximum value required to prevent movement

13 through the soil profile. The resulting metabolite, which is in fact the active substance,

14 was modeled for degradation using the experimentally determined $t_{1 / 2}$ data $\left(t_{1 / 2}(1)\right)$. In

15 the current work, the new modeling approach involves the use of the half-life time

16 determined from the water release kinetics experiments as $\mathrm{t}_{1 / 2}(2)$.

\section{Adsorption and dissipation experiments}

Non-treated soil adjacent to the field experiment was sampled for incubation and adsorption experiments. Incubation experiments were done in triplicate by adding

21 alachlor ( $3 \mathrm{mg} \mathrm{kg}^{-1}$ soil) to $200 \mathrm{~g}$ of air-dried soil. After shaking thoroughly for $24 \mathrm{~h}$, the 22 soil was transferred to plastic pots, covered with aluminum foil and incubated in the dark for 2 weeks at $20^{\circ} \mathrm{C}$. The soil moisture content was maintained at field capacity by

24 the periodic addition of water. Soil samples ( $2 \mathrm{~g})$ were taken every two or three consecutive days, extracted with methanol, and the herbicide content was determined. 
Adsorption experiments were done by equilibrating $2 \mathrm{~g}$ of untreated soil with

$210 \mathrm{~mL}$ of alachlor solutions of concentrations up to $20 \mathrm{mg} \mathrm{L}^{-1}$ for $24 \mathrm{~h}$ at $20^{\circ} \mathrm{C}$. The

3 supernatants were centrifuged and analyzed for the herbicide. The amount of adsorbed

4 alachlor was calculated from the difference between the initial and equilibrium solution

5 concentrations. The experimental points were fitted to the Freundlich equation (Conc.

6 sorbed $=\mathrm{K}_{\mathrm{f}}$ Conc. $_{\text {water }}{ }^{1 / \mathrm{n}}$ ) and $\mathrm{K}_{\mathrm{om}}$ was successively determined from the value of the

7 sorption coefficient $\mathrm{K}_{\mathrm{f}}$ normalized to the soil organic matter content.

8

\section{Data analysis}

A one-way ANOVA was used to analyze differences in crop yield among the different formulations. The means were compared with the Student's t-test $(\alpha=0.05)$, using SAS software (SAS Institute, 2008). The residual amounts of herbicide from each depth studied were analyzed using the standard error as a pooled estimate.

\section{RESULTS}

\section{Active ingredient and encapsulation efficiency}

Table 1 shows the characteristics of the formulations used in the field experiments. The active ingredient (a.i.) contents in the PC-clay formulations were $15.0 \%$ and $39.5 \%$ for the A5/8 and A1.6/14 formulations, respectively. The a.i. content of the A5/8 formulation was quite close to that of the A18 formulation. The a.i. content of the A1.6/14 formulation was similar to the a.i. content of the commercial formulation $(48 \%)$.

The encapsulation efficacy (EE) of the herbicide was defined as the ratio between the amount of alachlor that was incorporated into the microspheres or the PCclay complex and the amount added to the system. The PC-clay complex A1.6/14 was 
1 the best system for incorporating the herbicide, which is of economical interest in the

2 preparation of herbicide formulations.

3

6 formulations as well as the solubility profile for technical grade alachlor. The release 7 pattern from the PC-clay formulations (A5/8 and A1.6/14) was similar during the first 7

8 h. In both cases, the initial release was fast, reaching complete release at the end of the

9 experiment. The release from EC formulations was significantly slower and complete 10 release was not measurable.

\section{Water release kinetics}

Figure 1 shows the cumulative release of alachlor from PC-clay and EC The kinetics of alachlor release from the PC-clay and EC formulations was analyzed by fitting the data to the generalized model of Ritger and Peppas (1987)

$$
\mathrm{Mt} / \mathrm{Mo}=\mathrm{K} \mathrm{t}^{\mathrm{n}} \quad[\mathrm{Eq} .1]
$$

where $\mathrm{Mt}$ is the amount of herbicide released from the formulations at any time $\mathrm{t}$, Mo is the total initial amount of herbicide in the system, $\mathrm{K}$ is a constant that incorporates the characteristics of the macromolecular network system, and $\mathrm{n}$ is an exponent that indicates the mechanism of release. It should be noted that this expression is valid for a limited time span since it cannot be extended to infinite values of t. Ignoring a residual adsorbed fraction of alachlor at equilibrium is permissible because the concentrations of the formulations were very small.

According to the correlation coefficients, the experimental data were well-fitted by the Ritger and Peppas equation (Table 2). The exponential $n$ values in Eq. 1 were about 0.48 and 0.55 for the PC-clay complexes, whereas lower values of 0.42 and 0.43 were obtained for the EC formulations. It has been reported that in cases of pure Fickian release, the exponent $\mathrm{n}$ has the limiting value of 0.50 and 0.43 for release from slabs and 
1 spheres, respectively (Ritger and Peppas, 1987). Consequently, the mechanism of

2 alachlor release from EC and PC-clay formulations is close to a Fickian controlled

3 diffusion process. This mechanism has been already reported for norflurazon EC

4 microspheres (Sopeña et al., 2005).

The $\mathrm{t}_{1 / 2}$ values (the times at which $50 \%$ of the herbicide is released) were

6 deduced from the $\mathrm{K}$ and $\mathrm{n}$ constants (Table 2 ). These $t_{1 / 2}$ values are those defined as $t_{1 / 2}$

7 (2) in the modeling scheme. The $t_{1 / 2}$ values were extremely high for EC formulations.

8 For example, the $\mathrm{t}_{1 / 2}$ values for the two formulations containing practically the same a.i.

9 content, A18 and A5/8, were 51-fold larger for the EC formulations. The capability of

10 using these $t_{1 / 2}$ values in the model arises from the fact that the release curves were also

11 well-fitted to a first order kinetics equation (data not shown), and therefore the release

12 times were independent of the herbicide concentration used in the in-vitro experiments.

\section{Alachlor distribution in the soil profile}

The extracted amounts of alachlor in the soil core columns after the three

16 samplings are shown in Fig. 2 and Table 3. The total amount of alachlor remaining in

17 the 0 - to $30-\mathrm{cm}$ depth was similar for the first and second samplings for the commercial and PC-clay formulations. The percentages of the total alachlor applied remaining in the

19 soil after $59 \mathrm{~d}$ were $76.7 \pm 6.4$ for the commercial formulation, $82.5 \pm 7.7$ for $\mathrm{A} 5 / 8$, $2082.9 \pm 4.6$ for A1.6/14, 87.1 \pm 18.0 for A14 and $100.1 \pm 7.3$ for A18. After $247 \mathrm{~mm}$ of rain

21 (third sampling, 191 DAT), the retained amounts of alachlor for the commercial and 22 PC-clay formulations were still similar: $56.7 \pm 3.0,55.5 \pm 2.5$ and $52.9 \pm 6.2 \%$ for the commercial, A5/8, and A1.6/14, respectively. The EC formulations exhibited, however,

24 much higher recoveries, $74.5 \pm 10.7 \%$ for A14 and $98.7 \pm 7.9 \%$ for A18. 
Fig. 2a shows that for the first soil sampling, which corresponded to $46 \mathrm{~mm}$

2 of cumulative rainfall, the amount of alachlor was larger in the $0-$ to $10-\mathrm{cm}$ depth for

3 the PC-clay and EC formulations than for the commercial formulation. The increase of

4 alachlor amounts with respect to the commercial formulation was $28.8 \%$ for $\mathrm{A} 5 / 8$,

$536.6 \%$ for $\mathrm{A} 1.6 / 14,42.7 \%$ for $\mathrm{A} 14$, and $100 \%$ for A18. In the next layer, there was a

6 larger accumulation of the herbicide from the commercial formulation than from the

7 SRFs. At $99 \mathrm{~d}$ and $112 \mathrm{~mm}$ of cumulative rainfall (Fig. 2b), the amount of alachlor in

8 the 0 - to $10-\mathrm{cm}$ soil layer was reduced for the commercial and PC-clay formulations.

9 There was still, however, a significant difference in the top layer soil between the 10 commercial formulation and SRFs.

11 At $191 \mathrm{~d}$ and $247 \mathrm{~mm}$ of cumulative rainfall (Fig. 2c), the recovered amounts

12 from the 0 - to $10 \mathrm{-cm}$ depth were significantly larger for the SRFs than for the 13 commercial formulation. The accumulated amounts of alachlor at the 20- to $30-\mathrm{cm}$

14 depth were much larger for the commercial formulation than for SRFs. The lower 15 recovery of the herbicide from PC-clay and EC formulations at the 20- to $30-\mathrm{cm}$ depth 16 and the greater recovery at the $0-$ to $10-\mathrm{cm}$ depth imply that the use of these 17 formulations reduces leaching of alachlor over the commercial formulation.

The bioefficacy of the commercial and slow release formulations at the end

19 of the field experiment was determined (Table 4). The reductions in fresh weight with 20 respect to the control were $48.3 \%, 52.4 \%$, and $57.2 \%$ for the commercial, A5/8 and 21 A1.6/14 formulations, respectively, but no significant difference in the yield of the crop 22 was observed. In contrast, EC formulations did not lead to any reduction in the fresh 23 weight, as their yield was comparable to the control. 
The experimental and calculated distribution of alachlor is shown in Table 3.

2 In this analysis, values of $\mathrm{K}_{\mathrm{om}}$ and degradation half-life time of $2.13 \mathrm{~L} \mathrm{~kg}^{-1}$ and 13 days,

3 as determined previously from adsorption and incubation experiments in non-treated

4 soil, were used. The release half-lives determined in the water release kinetics

5 experiment (Table 2) were used to model the SRFs. In general, the predicted amounts

6 agreed quite well with the measured amounts 59 and 99 days after treatment (DAT) for

7 the commercial and the slow release formulations (RMSE $=6.3 \%$ and $4.2 \%$,

8 respectively). In the upper layer of soil, the residual amounts of herbicide from the

9 commercial formulation were always overestimated. In PC-clay formulations, the

10 experimental values were slightly underestimated for the model at 59 DAT and

11 overestimated at 99 DAT, but the overall agreement with the predicted values was very

12 good. In contrast, the opposite trend was seen for the EC formulations, whose calculated

13 values were overestimated after 59 DAT and underestimated after 99 DAT. There was

14 very good agreement between the predictions of the model and the experimental

15 amounts for A14 at 99 DAT. For all formulations, there was generally good agreement

16 between the experimental and predicted amounts at the lower depths.

The predictions of the herbicide distribution in the soil were not adequate at

191 DAT (RMSE=12.5\%). The differences in the upper layer became more

19 pronounced, especially for the commercial and PC-clay formulations, whose calculated

20 amounts were overestimated by $19-23 \%$. With the EC formulations, the predicted

21 amount was quite close to the experimental amount for A18, but there was no good

22 correspondence between the experimental and predicted amounts for A14. In the

23 following segment, the model largely overestimated the residual amounts in the soil for

24 the commercial and PC-clay formulations by $13 \%$, whereas the agreement was better 
1 for EC formulations. At a depth of 20- to $30-\mathrm{cm}$, the predictions were quite good with

2 the exception of the commercial formulation.

3

6 showed very slow herbicide dissipation. The high persistence of alachlor may be

7 explained by: (i) the effect of the herbicide concentration on the soil microbial activity;

8 (ii) climatic factors, such as temperature and soil moisture content; and (iii) the effect of

9 drying and wetting cycles on the soil. In the case of SRFs, an additional factor is the

10 protection of the active ingredient through its inclusion in a matrix, such as PC-clay or

11 EC, which slows its release and field dissipation.

Alachlor behavior in soil is influenced by the organic carbon content. Its interaction with organic matter has been reported to occur mainly via physical adsorption processes, such as weak induction or dispersion forces (Patakioutas and Albanis, 2002). There is a strong correlation between its persistence and sorption, which determines the remaining fraction of herbicide that is immediately available for different dissipation mechanisms. The vapor pressure of alachlor is low and losses by volatilization and photolysis in the soil are not significant. The main pathway for alachlor dissipation in soils is through microbial degradation (Tomlin, 2003). Sopeña et al. (2008) found a strong correlation between the soil dehydrogenase activity, and alachlor dissipation in a soil similar to that examined in our study. Felsot and Dzantor (1995) reported that alachlor inhibited this enzyme at very low concentrations, and caused prolonged inhibition for at least $21 \mathrm{~d}$ at concentrations $\geq 750 \mathrm{mg} \mathrm{kg}^{-1}$. The amounts of herbicide extracted with methanol account for its bioavailable bound residues, which prolong its herbicidal activity on the microbial flora, because of the low 
1 organic carbon content of this soil combined with the weak interactions of the herbicide

2 with the organic matter.

3

4

The low rate of alachlor dissipation can also be attributed to the generally low temperatures (Fig. 3). Yen et al. (2005) reported that the half-life of alachlor increased from 68 to $187 \mathrm{~d}$ when decreasing the incubation temperature decreased from $25^{\circ} \mathrm{C}$ to $10^{\circ} \mathrm{C}$ at a soil moisture content of $90 \%$ of the field capacity. The temperatures recorded during our experiment were in the range of 8 - to $13{ }^{\circ} \mathrm{C}$ range, with the exception of the last month and a half, which had higher values $\left(\sim 17-20^{\circ} \mathrm{C}\right)$.

The rainfall (Fig. 3) was very irregular, with intervals of dry periods. GarcíaValcárcel and Tadeo (1999) reported that drying and rewetting cycles of soil yielded lower degradation rate of the herbicides simazine and hexazinone, compared to soil incubated in the same range of constant soil moisture. Therefore, the effect of alternating drying and wetting periods would give a lower herbicide degradation rate, partly explaining the high persistence of alachlor.

This study demonstrates a reduction in the leaching of alachlor from PC-clay and EC formulations compared to that from the commercial formulation. The reduction in leaching was reflected by the larger extracted amounts of herbicide after 191 DAT in the 0 - to $10-\mathrm{cm}$ layer of the soil together with the lower extracted amounts in the 20- to $30-\mathrm{cm}$ depth relative to the commercial formulation. In the top soil layer, bioefficacy of the SRFs was maintained only in the PC-clay formulations.

The poor performance of the EC formulations in terms of maintaining the herbicide bioefficacy was due to the low release constant of the herbicide from the matrix. Previous laboratory studies (Sopeña et al. 2007; 2008) have reported that these EC formulations significantly reduced the dissipation and leaching of alachlor. The differences in performance of EC formulations under laboratory vs. field conditions 
1 may be related to the soil moisture. The occurrence of rainfall is a major factor in

2 herbicide release from granular SRFs immediately after application. The granules must

3 be wetted to enable permeation of the active ingredient through the microcapsule shell

4 and its diffusion into the soil solution before it can move through the soil and be

5 available for pest control. The oscillation in soil moisture content, or the effect of drying

6 and wetting cycles is believed to reduce herbicide release and create several lag times in

7 the release profile, producing sub-threshold concentrations of alachlor in the soil matrix.

8 In addition, EC formulations have an average particle size distribution in the range of

9100 to $400 \mu \mathrm{m}$ (Sopeña et al., 2009), which makes the wetting of the granules under low

10 rainfall events more difficult in comparison to $\mathrm{PC}$ formulations, which have a particle

11 size of around $2 \mu \mathrm{m}$.

12 The model yielded good predictions at times of 99 DAT. For longer times

13 (191 DAT), a discrepancy was recorded between the experimental and predicted

14 amounts of the herbicide in the top soil layer (Table 3). The model overestimated the

15 concentration of alachlor, which may be partly explained by an enhanced degradation of

16 the herbicide following adaptation of the microbial populations. Scorza and Boesten

17 (2005) reduced the half-life of bentazone by 2.5 -fold in order to simulate its leaching.

18 Hence, in our study, calculations were performed to account for this effect by

19 decreasing the half-life of alachlor. The inaccuracy in the calculated values was largely

20 reduced by employing a 1.6-fold reduction in its half-life ( 8 days) for the period

21 between 99 and 191 DAT. The predicted values in the $0-$ to $10-\mathrm{cm}$ depth were $21.5 \%$

22 for the commercial formulation, $26.3 \%$ for $\mathrm{A} 5 / 8,28.3 \%$ for $\mathrm{A} 1.6 / 14,31.1 \%$ for $\mathrm{A} 14$

23 and $44.1 \%$ for A18. This improved fitting was expressed by a much lower RMSE

$24 \quad(7.9 \%$ versus $18.0 \%)$. 
Another source of uncertainty in the predictions may arise from herbicide

2 aging in the soil, which the model does not account for: this process does not occur

3 when determining the half-life of alachlor under laboratory conditions due to its

4 relatively rapid degradation. Because of this aging, the fraction of extractable residues

5 decreases at the expense of non-extractable /recalcitrant residues, resulting in a

6 reduction in the bioavailability and degradation of the herbicide (Boivin et al., 2004).

7 This fraction is included in the calculations, but is not susceptible to leaching and

8 degradation processes; therefore, the calculations will yield an overestimation of the

9 residual amounts in the soil, as noted in Table 3. The effect of sequestration of the

10 active compound in the soil is manifested by the difficulty in extracting part of this

11 recalcitrant fraction, which requires increasingly harsh solvents (Taylor et al., 2005).

12 There is a good correlation between bioavailability and the soil fraction extracted with 13 methanol (Kelsey et al., 1997; Barriuso et al., 2004). A sequential extraction after

14 methanol with a mixture of acetone/ethyl acetate/water (AEW) (2:2:1 v:v) will extract

15 some of the recalcitrant fractions (Laabs and Amelung, 2005). This sequential

16 extraction was performed after $191 \mathrm{~d}$ for the commercial and the PC-clay formulations,

17 where a longer aging period for the herbicide is expected due to the longer residence

18 time of the free herbicide in the soil. With EC formulations, in which the active

19 ingredient is retained for longer periods within the EC matrix, herbicide aging is less

20 important. The AEW-desorbed fractions in the top soil layer amounted to $15.2 \pm 7.4 \%$,

$2110.5 \pm 0.3 \%$, and $10.1 \pm 1.5 \%$ for the commercial, A5/8, and A1.6/14 formulations,

22 respectively. These AEW recoveries are indicative of the aging of the herbicide in the

23 soil, but the aged fraction of the herbicide might account for a larger amount than that

24 determined by AEW extraction, since there could be an important fraction of the

25 herbicide incorporated into the soil matrix by abiotic processes. 


\section{CONCLUSIONS}

3

This study clearly showed reduced leaching of alachlor from PC-clay and EC

4 formulations as compared to the commercial formulation. In the top soil layer,

5 alachlor's bioefficacy was only maintained with the PC-clay formulation: the very slow

6 release from the EC formulations results in herbicide concentrations in the soil solution

7 that are too low to be effective.

The persistence of the herbicide in field experiments was much longer than that

9 determined in the laboratory under constant temperature and moisture conditions. This

10 can be explained mainly by climatic factors, such as oscillations in temperature and soil

11 moisture content, or by the effect of drying and wetting cycles on the bioavailability of

12 the herbicide in the soil. In the case of SRFs, an additional factor is protection of the

13 active ingredient through its inclusion in a matrix which limits the herbicide's exposure

14 to environmental factors, slowing its dissipation in the field.

15 Tests of the pesticide-leaching model PEARL demonstrated good prediction for the 16 experimental distribution in the soil profile at 59 and 99 DAT; however, a large 17 discrepancy was noted between the calculated and experimental values at the end of the experiment (191 DAT). The implication may be that the model has to account for two additional effects: (i) the adaptation time of the microbial population for degrading the herbicide and (ii) the effect of herbicide sequestration in the soil matrix by a process

\section{1 denoted as "aging".}




\section{REFERENCES}

2 Barriuso, E., W.C. Koskinen, and M.J. Sadowsky. 2004. Solvent extraction characterization of bioavailability of atrazine residues in soils. J. Agric. Food Chem. 52: 6552-6556.

Boivin, A., R. Cherrier, C. Perrin-Ganier, and M. Schiavon. 2004. Time effect on bentazone sorption and degradation in soil. Pesticide Manag. Sci. 60: 809-814.

Boparai, H., P. Shea, S. Comfort, and D. Snow. 2006. Dechlorinating chloroacetanilide herbicides by dithionite-treated aquifer sediment and surface soil. Environ. Sci. Technol. 40: 3043-3049.

Felsot, A.S., and E.K. Dzantor. 1995. Effect of alachlor concentration and an organic amendment on soil dehydrogenase activity and pesticide degradation rate. Environ. Toxicol. Chem. 14: 23-28.

Fernández-Urrusuno, R., J.M. Ginés, and E. Morillo. 2000. Development of controlled release formulations of alachlor in ethylcellulose. J. Microencapsulation 17: 331342.

Ford, S.C., O.R. Price, and A.S. Terry. 2007. Transport of pesticides to water from slow release formulations: Application of current pesticide fate models. p. 503-510. In Del Re, A.A.M., Capri, E., Fragoulis, G. \& Trevisan, M. (eds.) Environmental Fate and Ecological Effects of Pesticides. XIII Symposium Pesticide Chemistry, Piacenza, Italy. 6-7 Sept. La Goliardica Pavese, Pavia.

García-Valcárcel, A.I., and J.L. Tadeo. 1999. Influence of soil moisture on sorption and degradation of hexazinone and simazine in soil. J. Agric. Food Chem. 47: 38953900. 
1 Kelsey, J.W., B.D. Kottler, and M. Alexander. 1997. Selective chemical extractants to predict bioavailability of soil-aged organic chemicals. Environ. Sci. Technol. 31: 214-217.

Laabs, V., and W. Amelung. 2005. Sorption and aging of corn and soybean pesticides in tropical soils of Brazil. J. Agric. Food Chem. 53: 7184-7192.

Mishael, Y., T. Undabeytia, G. Rytwo, B. Papahadjopoulos-Sternberg, B. Rubin, and S. Nir. 2002a. Sulfometuron incorporation in cationic micelles adsorbed on montmorillonite. J. Agric. Food Chem. 50: 2856-2863.

Mishael, Y.G., T. Undabeytia, O. Rabinovitz, B. Rubin, and S. Nir. 2002b. Slow-release formulations of sulfometuron incorporated in micelles adsorbed on montmorillonite. J. Agric. Food Chem. 50: 2864-2869.

Mishael, Y.G., T. Undabeytia, O. Rabinovitz, B. Rubin, and S. Nir. 2003. Sulfosulfuron incorporated in micelles adsorbed on montmorillonite for slow release formulations. J. Agric. Food Chem. 51: 2253-2259.

Morillo, E., F. Sopeña, A. Cabrera, and C. Maqueda. 2004. Water release kinetics and soil mobility study of ethylcellulose-encapsulated norflurazon. In: Saturated \& Unsaturated Zone, Integration of process knowledge into effective models. La Goliardica Pavese; Pavia, Italy, pp. 205-210.

Mualem, Y. 1976. A new model for predicting the hydraulic conductivity of unsaturated porous media. Water Resources Res. 12: 513-522.

Nir, S., B. Rubin, Y.G. Mishael, T. Undabeytia, O. Rabinovitch, and T. Polubesova. 2006. Controlled release formulations of anionic herbicides. US Patent Document 7,030,062 B2. 
1 Patakioutas, G., and T. A. Albanis. 2002. Adsorption-desorption studies of alachlor, metolachlor, EPTC, chlorothalonil and pirimiphos-methyl in contrasting soils. Pest Manag. Sci. 58: 352-362.

Pérez-Martínez, J.I., E. Morillo, C. Maqueda, and J.M. Ginés. 2001. Ethylcellulose polymer microspheres for controlled release of norflurazon. Pest Manag. Sci. 57: 688-694.

Ritger, P., and N. Peppas. 1987. A simple equation for description of solute release I. Fickian and non-Fickian release from non-swellable devices in the form of slabs, spheres, cylinders or discs. J. Controlled Release 5: 37-42.

Sánchez-Camazano, M., L.F. Lorenzo, and M.J. Sánchez-Martín. 2005. Atrazine and alachlor inputs to surface and groundwaters in irrigated corn cultivations areas of Castilla-León region, Spain. Environ. Monit. Assessment 105: 11-24.

Sánchez-Verdejo, T., T. Undabeytia, S. Nir, C. Maqueda, and E. Morillo. 2008a. Environmentally friendly slow release formulations of alachlor based on clayphosphatidylcholine. Environ. Sci. Technol. 42: 5779-5784.

Sánchez-Verdejo, T., T. Undabeytia, S. Nir, J. Villaverde, C. Maqueda, and E. Morillo. 2008b. Environmentally friendly formulations of alachlor and atrazine: Preparation, characterization and reduced leaching. J. Agric. Food Chem. 56: 10192-10199.

Scorza, R.P.Jr., and J.J.T.I. Boesten. 2005. Simulation of pesticide leaching in a cracking clay soil with the PEARL model. Pest Manag. Sci. 61: 432-448.

Sopeña, F., A. Cabrera, C. Maqueda, and E. Morillo. 2005. Controlled release of the herbicide norflurazon into water from ethylcellulose formulations. J. Agric. Food Chem. 53: 3540-3547. 
1 Sopeña, F., A. Cabrera, C. Maqueda, and E. Morillo. 2007. Ethylcellulose formulations for controlled release of the herbicide alachlor in a sandy soil. J. Agric. Food Chem. 55: 8200-8205.

Sopeña, F., C. Maqueda, and E. Morillo. 2008. Influence of soil characteristics and formulation on alachlor dissipation in soil. Soil Sci. Soc. Am. J. 72: 767-774.

Sopeña, F., C. Maqueda, and E. Morillo. 2009. Formulation affecting alachlor efficacy and persistence in sandy soils. Pest Manag. Sci. 65: 761-768.

Taylor, J.P., M.S. Mills, and R.G. Burns. 2005. Dissipation of acetochlor and its distribution in surface and sub-surface soil fractions during laboratory incubations. Pest Manag. Sci. 61: 539-548.

Tiktak, A., F. van den Berg, J.J.T.I. Boesten, D. van Kraalingen, M. Leistra, and A.M.A. van der Linden. Manual of FOCUS PEARL, versión 1.1.1.; RIVM Report 711401 008; Alterra Report 28; Bilthoven: Wageningen, The Netherlands, 2000.

Tomlin, C.D.S. 2003. The Pesticide Manual: A world compendium. $13^{\text {th }}$ ed. British Crop Protection Council, Berks, UK.

Undabeytia, T., Y.G. Mishael, S. Nir, B. Papahadjopoulos-Sternberg, B. Rubin, E. Morillo, and C. Maqueda. 2003. A novel system for reducing leaching from formulations of anionic herbicides: Clay-liposomes. Environ. Sci. Technol. 37: 4475-4480.

Undabeytia, T., S. Nir, and M.J. Gomara. 2004. Clay-vesicle interactions: fluorescence measurements and structural implications for slow release formulations of herbicides. Langmuir 20: 6605-6610.

Van Genuchten, M.Th. 1980. A closed form equation for predicting the hydraulic conductivity of unsaturated soils. Soil Sci. Soc. Am. J. 44: 892-898. 
1 Weber, J., G. Mahnken, and L. Swain. 1999. Evaporative effects on mobility of C-14 labeled triasulfuron and chlorsulfuron in soils. Soil Sci. 164: 417-427.

3 Yen, J-H., S-L. Chang, C-C. Wu, and Y-S. Wang. 2005. Behavior of acetanilide 4 herbicides in soils and the possibility of groundwater contamination. Bull. 5 Environ. Contam. Toxicol. 75: 1086-1093.

6 


\section{Figure legends.}

2 Figure 1. Cumulative release of alachlor in in vitro experiments from the technical product $(\boldsymbol{\bullet})$, and the slow-release formulations A5/8 $(\bullet)$, A1.6/14 ( $\mathbf{\Delta})$, A18 ( $\mathbf{\nabla})$ and A14 (४).

5 Figure 2. Alachlor distribution from commercial and slow-release formulations as a function of soil depth 59 (a), 99 (b) and 191 (c) days after treatment. Means followed by the same letter by each formulation by each depth for each period of sampling are not significantly different according to Student's multiple range test at $P=0.05$. Vertical bars show standard errors.

10 Figure 3 . Fortnightly average precipitation $\left(\mathrm{mm}\right.$ rain) $(\bullet)$ and air temperature $\left({ }^{\circ} \mathrm{C}\right)$ during the field experiment. 
Table 1. Characterization of alachlor formulations based on EC and PC-clay in this study.

\begin{tabular}{cccc}
\hline $\begin{array}{c}\text { Formulant } \\
\text { material }\end{array}$ & Notation & Active ingredient & Encapsulation Efficacy (EE) \\
\hline PC-clay & A5/8 & 15.0 & $(\%)$ \\
PC-clay & A1.6/14 content $(\%)$ & 78 \\
Ethylcellulose & A14 & 39.5 & 97 \\
Ethylcellulose & A18 & 20.6 & 75 \\
& & 13.8 & 70 \\
\hline
\end{tabular}


Table 2. Parameters deduced from simulations of alachlor release in water by Eq. (1).

\begin{tabular}{ccccc}
\hline Formulation & $\mathrm{K}(\mathrm{h})^{-\mathrm{n}}$ & $\mathrm{n}$ & $\mathrm{R}^{2}$ & $\mathrm{t}_{1 / 2}(\mathrm{~h})$ \\
\hline A5/8 & 14.06 & 0.48 & 0.992 & 18 \\
$\mathrm{~A} 1.6 / 14$ & 14.07 & 0.55 & 0.995 & 15 \\
$\mathrm{~A} 14$ & 3.52 & 0.42 & 0.998 & 576 \\
$\mathrm{~A} 18$ & 2.71 & 0.43 & 0.996 & 912 \\
\hline
\end{tabular}


Table 3. Experimental (Exp.) and calculated (Calc.) distribution of alachlor along the soil profile expressed as percent of the total amount applied, after 59, 99 and 191 days after treatment. $\dagger$

\section{Soil depth}

$0-10 \mathrm{~cm} \quad 10-20 \mathrm{~cm} \quad 20-30 \mathrm{~cm}$

\begin{tabular}{|c|c|c|c|c|c|c|c|}
\hline & \multicolumn{2}{|c|}{$0-10 \mathrm{~cm}$} & \multicolumn{2}{|c|}{$10-20 \mathrm{~cm}$} & \multicolumn{2}{|c|}{$20-30 \mathrm{~cm}$} \\
\hline & & $\operatorname{Exp}$ & Calc & $\operatorname{Exp}$ & Calc & Exp & Calc \\
\hline \multirow{5}{*}{$59 \mathrm{DAT}$} & Com & $35.8 \pm 1.3 \ddagger$ & 40.0 & $30.2 \pm 4.2$ & 28.7 & $10.7 \pm 0.9$ & 18.6 \\
\hline & $\mathrm{A} 5 / 8$ & $46.1 \pm 2.8$ & 43.3 & $22.9 \pm 1.4$ & 29.7 & $13.5 \pm 1.4$ & 19.1 \\
\hline & A1.6/14 & $49.0 \pm 1.0$ & 43.2 & $20.7 \pm 2.8$ & 29.7 & $13.2 \pm 0.8$ & 19.3 \\
\hline & A14 & $51.1 \pm 4.3$ & 58.3 & $19.8 \pm 3.8$ & 17.6 & $16.2 \pm 6.9$ & 8.4 \\
\hline & A18 & $70.0 \pm 9.2$ & 79.6 & $16.8 \pm 0.5$ & 12.6 & $13.3 \pm 1.6$ & 6.1 \\
\hline \multirow{5}{*}{$99 \mathrm{DAT}$} & Com & $28.2 \pm 1.7$ & 33.6 & $29.0 \pm 0.9$ & 27.5 & $22.1 \pm 1.7$ & 17.7 \\
\hline & A5/8 & $35.1 \pm 0.2$ & 41.7 & $26.9 \pm 1.5$ & 28.5 & $17.9 \pm 0.3$ & 18.2 \\
\hline & A1.6/14 & $37.7 \pm 3.9$ & 42.0 & $23.5 \pm 0.5$ & 28.3 & $19.7 \pm 2.1$ & 18.0 \\
\hline & A14 & $53.2 \pm 6.5$ & 52.7 & $16.8 \pm 2.3$ & 20.6 & $17.7 \pm 1.6$ & 13.0 \\
\hline & A18 & $63.0 \pm 5.9$ & 57.3 & $20.3 \pm 0.4$ & 18.2 & $18.5 \pm 0.8$ & 11.5 \\
\hline \multirow{5}{*}{$191 \mathrm{DAT}$} & Com & $14.6 \pm 1.6$ & 33.4 & $14.5 \pm 0.1$ & 27.3 & $27.6 \pm 1.3$ & 17.8 \\
\hline & $\mathrm{A} 5 / 8$ & $18.5 \pm 1.9$ & 41.5 & $15.8 \pm 0.5$ & 28.2 & $21.2 \pm 0.1$ & 18.1 \\
\hline & A1.6/14 & $19.0 \pm 1.4$ & 41.7 & $15.1 \pm 3.1$ & 28.6 & $18.8 \pm 0.4$ & 18.0 \\
\hline & A14 & $35.1 \pm 6.5$ & 49.5 & $19.2 \pm 5.7$ & 21.7 & $20.2 \pm 6.5$ & 13.8 \\
\hline & A18 & $54.0 \pm 1.9$ & 49.8 & $30.2 \pm 4.4$ & 21.0 & $14.5 \pm 1.6$ & 13.9 \\
\hline
\end{tabular}

$\dagger$. The root mean square error (RMSE) was $6.3 \%$ for 59 DAT, $4.2 \%$ for 99 DAT and $12.5 \%$ for 191 DAT.

†. Plus/ minus standard error. 
Table 4. Avena yield as affected by alachlor formulation. ${ }^{\dagger}$

\begin{tabular}{cc}
\hline Formulation & Avena yield $\left(\mathrm{Mg} \mathrm{ha}^{-1}\right)$ \\
\hline None & $69.7 \mathrm{~A}$ \\
Commercial & $36.0 \mathrm{~B}$ \\
A5/8 & $33.1 \mathrm{~B}$ \\
A1.6/14 & 29.8B \\
A14 & 59.5A \\
A18 & $7.05 \mathrm{~A}$ \\
\hline$\dagger$. Means with the same letter are not significantly different at $P=0.05$ as determined by \\
Student's multiple range test.
\end{tabular}




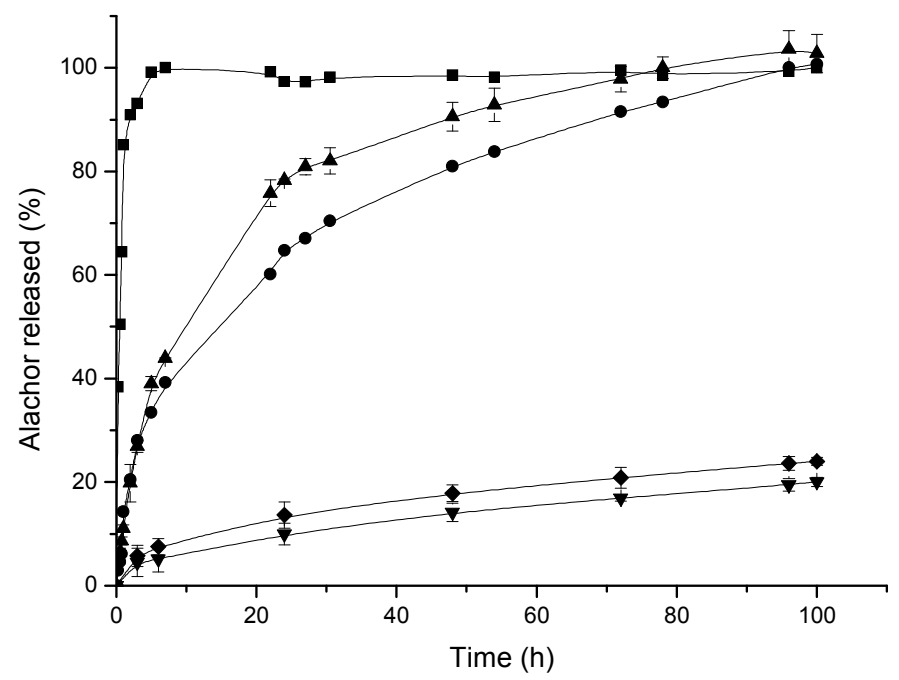

Figure 1 

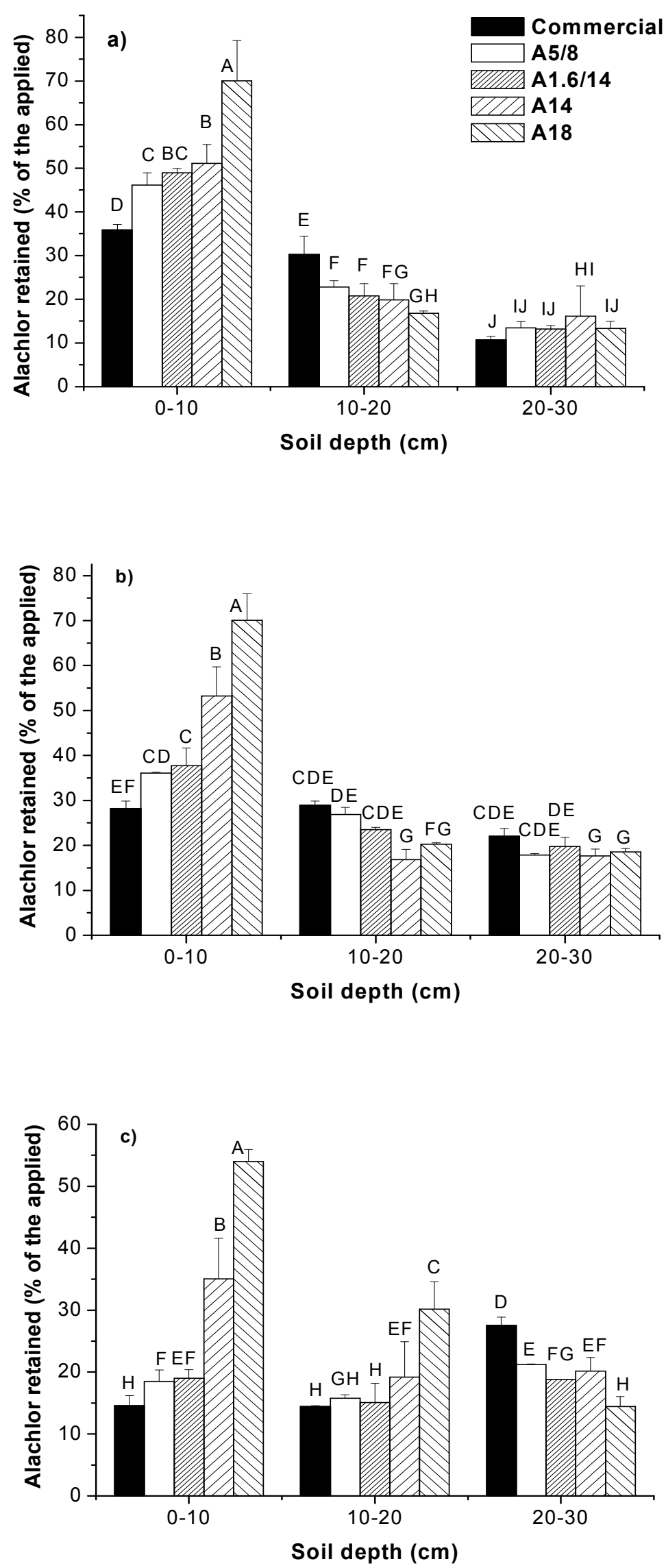

Figure 2 


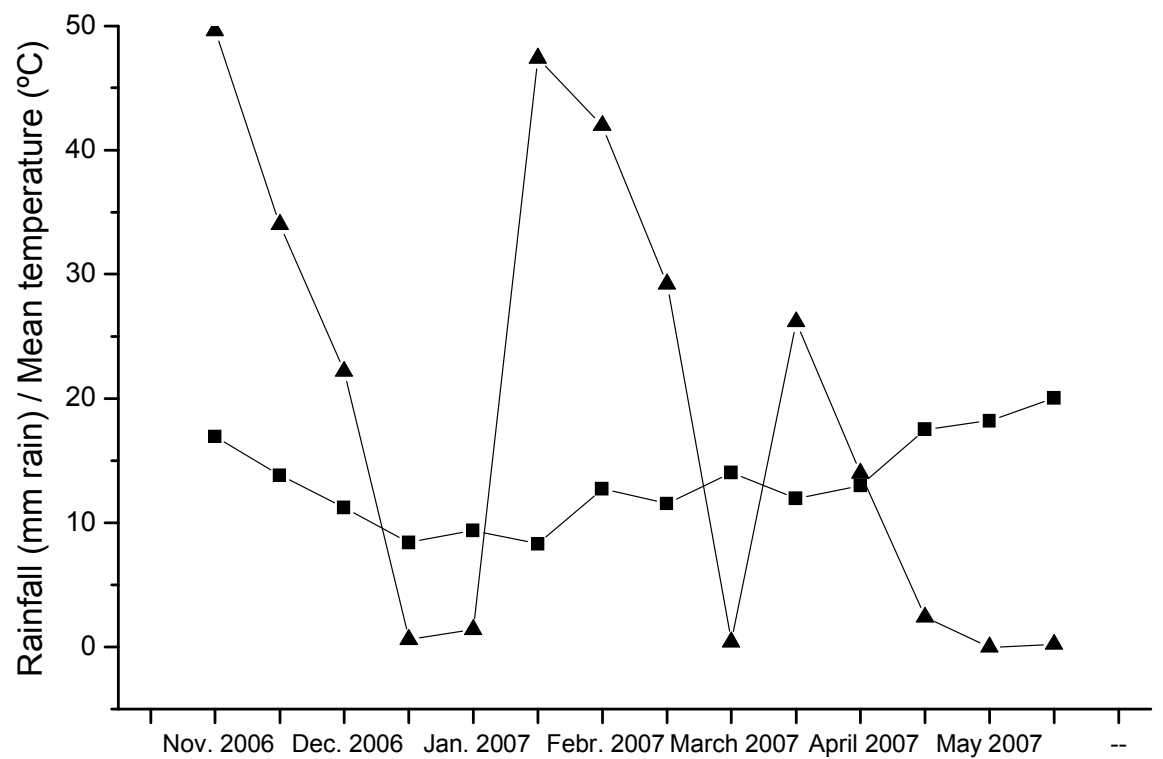

Figure 3 